\title{
Аксиологические трансформации в корпоративных изданиях: проблема дегуманизации медиаконтента
}

\author{
Семашкина Н.C. \\ Белгородский государственный национальный исследовательский университет, \\ Россия, 3008015, г. Белгород, ул. Победы, 85, \\ E-mail: pressasns@mail.ru
}

\begin{abstract}
Аннотация. Проблема ценностных изменений контента корпоративных изданий является одной из ключевых для современных исследований медиадискурса. В современной науке о медиа признается факт его дегуманизации, однако актуальной задачей является выявление сущностных аспектов этого процесса. Представленное исследование направлено на интерпретацию основных причин, направлений и характерных черт тенденции дегуманизации контента корпоративной прессы. Автор формулирует гипотезу о зависимости корпоративного медиаконтента от превалирующих текущих приоритетов компании. На примере изданий крупных коммерческих промышленных предприятий - Белгородского завода энергетического машиностроения и Объединенной металлургической компании проводится анализ аксиологической дифференциации корпоративного медиаконтента. Автором выявлен ряд закономерностей репрезентации человека в корпоративных публикациях в аспекте усиления тенденций дегуманизации корпоративного медиаконтента, в частности, смещение фокуса репрезентации от человека к ресурсам компании и коммерческому эффекту деятельности предприятия. Автор приходит к выводу о том, что одними из ключевых причин тенденций дегуманизации медиаконтента являются современные цифровые технологии и экономические реалии деятельности компаний.
\end{abstract}

Ключевые слова: корпоративный медиаконтент, корпоративные медиа, корпоративный медиадискурс, тенденции дегуманизации

Для цитирования: Семашкина Н.С. 2021. Аксиологические трансформации в корпоративных изданиях: проблема дегуманизации медиаконтента. Вопросы журналистики, педагогики, языкознания, 40 (4): 451-459. DOI: 10.52575/2712-7451-2021-40-4-451-459

\section{Axiological Transformations in Corporate Media: The Issue of Dehumanization of Media Content}

\author{
Nadezhda S. Semashkina \\ Belgorod National Research University, \\ 85 Pobeda St, Belgorod 308015, Russian Federation \\ E-mail: pressasns@mail.ru
}

\begin{abstract}
The issue of values changes of corporate media content lays as the one of central for contemporary media discourse analysis. The actual media studies regard as a fact the dehumanization of corporate media discourse, however the core aspects of this process are still insufficiently observed by researchers. The paper discusses the main reasons, trends and features of dehumanization of the corporate media discourse. The author claims the dependence of corporate media content on the prevailing actual priorities of a company. The author analyzes the axiological differentiation of content of corporate print media basing on several media of Russian large regional enterprises, such as Belgorod energetic machines building plant and United metallurgic company. The object of the study are the texts in issues of the corporate media of various years. The methods of the study are the traditional analysis of documents and content analysis of media. The paper shows the key patterns of representation of individuals in corporate media publications in terms of dehumanization. In particular, the author discusses the shift of
\end{abstract}


representation focus from the individual images and stories to the company's resources and commercial effects of the corporate activities. The results of the study contribute to the development of analytical methodology of corporate media and also to minimizing the tendencies of dehumanization of corporate media content. The author concludes that one of the important factors for dehumanization tendencies are modern digital technologies as well as the economic realities of enterprises.

Keywords: corporate media content, corporate media, corporate media discourse, dehumanization

For citation: Semashkina N.S. 2021. Axiological Transformations in Corporate Media: The Issue of Dehumanization of Media Content. Issues in Journalism, Education, Linguistics, 40 (4): 451-459 (in Russian). DOI: 10.52575/2712-7451-2021-40-4-451-459

\section{Введение}

Корпоративный медиаконтент представляет собой специфичный феномен социального информационного взаимодействия, цель которого состоит в поддержании и развитии характерной для компании или организации коммуникативной среды. Корпоративные медиа репрезентируют текущие значимые корпоративные события, основные направления деятельности организации, а также транслируют культивируемый компанией образ своего сотрудника, фактически выступая в качестве идентификационного ориентира для специалистов компании. В то же время в различных социально-экономических условиях, определяющих аксиологическую настройку политики организации, с помощью корпоративного медиадискурса транслируются различные ценностные модели репрезентации личности. Корпорации могут поддерживать антропоцентричные модели медиаконтента, в которых человек репрезентируется как ключевой элемент производственной системы и основополагающий критерий измерения эффективности корпоративной деятельности. В иных условиях доминирующими аксиологическими моделями могут выступать ресурсо- и эффектоцентрическая, а человек может быть нивелирован как значимый объект репрезентации.

Мы предполагаем, что тенденция дегуманизации характеризует актуальное состояние корпоративного медиадискурса. Если 10-15 лет назад это обстоятельство было обусловлено процессами коммерциализации и маркетизации производственных процессов, то сегодня существенным фактором дегуманизации выступают также процессы цифровизации и роботизации производства. Определение сущностных черт этой тенденции и ее основных проявлений в корпоративном медиаполе - одна из основных задач исследования современного корпоративного медиаконтента.

Терминологические аспекты исследования. Сегодня многие авторы рассматривают «медиаконтент» как обобщенное понятие, подразумевая под этим термином любой вид информации, составляющий содержание информационного продукта, и называя в качестве основных специфических признаков контента содержательную значимость для потребителя, соответствие его целям и потребностям [Павленко, 2017; Алексютина, 2018]. Само понятие используется как общеупотребительное по причине его широкого распространения в самых разных сферах общественной жизни. Широко применяемой является следующая интерпретация медиаконтента: «...любые данные - текст, звук, зрительные образы или комбинации мультимедийных данных, представленные в аналоговом или цифровом формате на разнообразных носителях, таких как бумага, микрофильм, магнитные или оптические запоминающие устройства» [Лукина, Вартанова, Фольц, 2010, с. 22]. В то же время, по определению Л.П. Шестеркиной и Л.К. Лободенко, медиаконтент представляет собой «совокупность широкого спектра медиатекстов (журналистских, рекламHых, PR и др.) структурно-содержательно упорядоченных в соответствии с концепцией и форматом конвергентного СМИ и ориентированных на интересы определенной целевой аудитории» [Шестеркина, Лободенко, 2014, с. 51]. 
Под корпоративным медиаконтентом в нашей работе мы будем рассматривать специализированное, содержательно значимое наполнение информационных медиаресурсов коммерческих предприятий, транслирующее корпоративные ценности и ориентированное на удовлетворение информационных потребностей целевой аудитории сотрудников организации.

В рамках нашего исследования обратимся к изучению медиаконтента корпоративных медиа Объединенной металлургической компании и завода «Белэнергомаш» (с февраля 2020 года входит в состав холдинга «ОМК»). Данные издания можно считать достаточно типичными для категории корпоративных медиа в аспекте периодичности, тиража, рубрикации, тематики, формата.

Теоретические рамки исследования. Основываясь на уже рассмотренных нами ценностных аспектах и аксиологических моделях корпоративного медиадискурса коммерческого предприятия [Семашкина, 2020], проанализируем процессы гуманитарной трансформации медиаконтента, обусловленные социальными метаморфозами, а также особенностями внутренних коммуникаций компании и корпоративной культуры. Это представляется важным в современных реалиях, когда «медиа стали тем контекстом, где обретают свои культурно-идеологические формы все социальные процессы» [Полонский, 2018, с. 233].

По мнению Н.Б. Гусаревой и К.Г. Царитовой, корпоративную культуру предприятия можно описать как «системное явление, комплекс различных инструментов управленческого воздействия» [Гусарева, Царитова, 2015, с. 28]. В числе наиболее часто упоминаемых компонентов исследователи называют миссию организации, стратегические цели корпорации, систему внешних и внутренних коммуникаций, ценности, убеждения, деловую этику, социально-психологический климат, методы отождествления индивида с корпорацией, формирования сопричастности человека с организацией, традиции (ритуалы, знаки корпоративной принадлежности и т.д.), документационное обеспечение [Гусарева, Царитова, 2015].

Б.С. Выпряжкин отмечает, что система ценностей, лежащая в основе организационной культуры - это «важнейшие атрибуты, которые формируют и определяют поведенческие нормы и рабочее поведение членов организации. Это совокупность материальных, духовных, социальных ценностей, созданных и создаваемых сотрудниками компании в процессе трудовой деятельности и отражающих неповторимость, индивидуальность данного предприятия» [Выпряжкин, 2011].

С точки зрения социального конструкционизма, Е. А. Кожемякин описывает медийную реальность как самостоятельную, относительно автономную по отношению к «объективному миру» и сформированную в соответствии с кодом, разделяемым внутри наблюдающей (конструирующей реальность) среды. Исследователь полагает, что массмедиа «транслируют ту действительность, которая выражает коллективные (профессионально-локальные или профессионально-сетевые) представления о реальном». Автор статьи разделяет эту точку зрения и, соответственно, утверждение о том, что создаваемая массмедиа «картина» - это не «зеркало действительности как объекта познания, а скорее проекция имманентных сообществу представлений о важном и незначительном, новом и старом, общем и уникальном и т. п.» [Кожемякин, 2013, с. 95]. На наш взгляд, данное утверждение в полной мере применимо и по отношению к корпоративным медиа.

\section{Объект и методы исследования}

Нами проанализированы 51 номер газеты «Трудовая слава» за 1988 год, 17 номеров газеты «Энергомаш» за 2003 год и 12 номеров газеты «Энергомаш» за 2018 год. Использованы метод традиционного анализа документов, контент-анализ и метод сплошной выборки. В качестве единиц анализа использованы фото, рубрики, тематика, риторико-стилистические и визуальные средства языка публикаций. Контент-анализ приме- 
нялся с целью проследить изменение корпоративного медиаконтента в зависимости от текущих экономических приоритетов компании, оценить динамику изменений тематики текстовых материалов.

\section{Результаты исследования}

Отметим, что во все периоды своего существования исследуемые корпоративные медиа стремились освещать актуальные события и самые интересные новости, рассказывать о передовиках производства, перспективах развития предприятия, строительстве новых объектах и планах модернизации. Можно утверждать, что система ценностей крупного промышленного предприятия репрезентирована в медиа посредством тематики, контекстуализации предмета сообщения, с помощью визуальных и других семиотических средств.

Трансформация медиаконтента, на наш взгляд, тесно связана с трансформацией современного общества, изменениями системы ценностей современного человека в целом и корпоративных ценностей крупных коммерческих предприятий в частности. Ранее нами уже выявлено, что в разные исторические периоды в корпоративном медиадискурсе завода «Белэнергомаш» доминировали различные аксиологические модели, в соответствии с которыми один и тот же предмет дискурса репрезентируется по-разному, с различными деталями, контекстами и фокусом внимания. В центре антропоцентрической модели - человек труда, передовики производства; ресурсоцентрической - вспомогательные средства, используемые при целевой деятельности сотрудников предприятия; эффектоцентрической - нацеленность на результат, коммерческий успех, производственные достижения и повышение конкурентоспособности предприятия. На примере корпоративных изданий Объединенной металлургической компании нами выделена и проанализирована клиентоцентрическая модель (ориентированная на повышение конкурентоспособности), также характеризующаяся дегуманизацией медиадискурса коммерческого предприятия.

Уточним, что антропоцентрическая модель корпоративного медиадискурса, по нашему мнению, характерна для 1970-х годов, ресурсоцентрическая становится преобладающей примерно с начала 1990-х годов, а эффектоцентрическая модель активно используется корпоративными медиа с 2010-х годов по настоящее время. Клиентоцентрическая модель доминирует в корпоративном медиадискурсе с конца 2020 года, при этом под словом «клиент» здесь традиционно понимается «потребитель услуг», а не человек сам по себе, в отрыве от экономических и корпоративных ценностей предприятия.

Для проведения контент-анализа нами были отобраны три корпоративных издания завода «Белэнергомаш»: газета «Трудовая слава» (1988 г.), газета «Энергомаш» (2003 г.) и газета «Энергомаш» (2018 г.). Временные интервалы в 15 лет и анализ подачи информации на страницах этих корпоративных медиа позволяют наглядно продемонстрировать, как смещался фокус репрезентации от человека на иные «корпоративные ценности».

«Tрудовая слава» - печатный орган парткома, профкома, комитета ВЛКСМ и дирекции производственного объединения «Белгородский завод энергетического машиностроения». Издание выпускается еженедельно, по пятницам. Тираж 1000 экземпляров. Газета издается с 5 ноября 1957 года (почти 20 лет - под названием «Белгородский котельщик» как печатный орган парткома, завкома и дирекции Белгородского котлостроительного завода; с 1977 года - как «Трудовая слава»). На 8 января 1988 года вышло в свет 1247 номеров, к концу года - 1297 (плюс 51 выпуск за год). Формат издания А3, 4 страницы, выходит в черно-белом варианте, верстка достаточно консервативна, шрифты не всегда удобочитаемы (мелкие), на фотографиях в фокусе внимания - человек (в среднем 3-4 портретных или групповых фото работников завода в каждом выпуске газеты).

Корпоративная газета освещает темы, близкие сотрудникам предприятия и членам их семей, внешняя аудитория (деловые партнеры, клиенты) практически не задействована. 
Активно используются визуальные средства оформления и передачи информации (фотографии, рисунки, разнообразные линейки и другие графические элементы).

В издании много материалов о сотрудниках завода и их профессиональных достижениях. Присутствует и производственная тематика, освещаются общественно-значимые мероприятия (итоги социалистического соревнования, отчеты о партийных конференциях и съездах). В некоторых выпусках на последней полосе имеется развлекательный контент: публикуются стихи сотрудников, библиографические обзоры, кроссворды, объявления.

Особенности контента можно охарактеризовать следующим образом: преобладают информационные жанры журналистики, портретные фотографии сотрудников и небольшие по объему текстовые зарисовки о них. Всего в газете за 1988 год использовано 45 рубрик, но лишь 10 из них можно назвать традиционными, среди них: «Реплика», «Проблемы производства», «Партийная жизнь», «Дневник соревнования», «Школа - ПТУ - объединение» и др. Некоторые рубрики в течение года использованы всего один-два раза. Отметим разнообразие рубрик к материалам партийной тематики («Политическая учеба», «Партийная жизнь», «К 70-летию ВЛКСМ», «Отчеты и выборы в партгруппах», «Обсуждаем тезисы ЦК КПСС», «Навстречу XIX Всесоюзной партконференции» и др.) при том, что в целом рубрикация в газете используется очень слабо, большинство материалов вообще не имеют рубрик и во многих выпусках их может быть по одной-две на целый номер. Вместе с тем традиционной рубрикой является «Газета выступила. Что сделано?», демонстрирующая заинтересованность аудитории и обратную связь с редакцией. Следует также выделить традиционные рубрики «Твои люди, завод» и «Наши люди - наша гордость», содержательно и тепло рассказывающие о передовиках производства.

На первой полосе каждого выпуска издания обязательно присутствует фотография и материал о лучших работниках завода. Для фотографий в целом характерна фокусировка на человеке труда. Из 198 фотографий, опубликованных в выпусках «Трудовой славы» за 1988 год, человек находится в центре внимания в 177 случаях $(89,4 \%)$. Это преимущественно портретные или групповые фотографии передовиков производства; фотографии производственных объектов и оборудования в газете практически отсутствуют. В отдельных выпусках содержатся жанровые пейзажные фотографии и иллюстрации к культурнопросветительским анонсам.

Наиболее часто в корпоративной газете «Трудовая слава» используются художественные жанры (очерк, житейская история, портретная зарисовка). Информационные жанры присутствуют в меньшей степени (заметки, информационная корреспонденция, отчеты). Иллюстративного материала много (в виде фотографий и рисунков).

Такой формат заводской газеты является вполне традиционным для корпоративного издания того времени. Типичным признаком времени можно считать явную «социалистическую» окрашенность значительной части публикаций. Вместе с тем очевидно, что газета действительно привлекает внимание аудитории (заводчан) и активно взаимодействует с ней.

Информационно-аналитическое издание «Энергомаш» - газета российских энергомашиностроителей (ОАО «Энергомашкорпорация»). Издается с 1999 года, печатается в Санкт-Петербурге, Барнауле, Белгороде, Волгодонске, Екатеринбурге общим тиражом 10 тыс. экземпляров. Выходит один раз в месяц (в мае, июне, июле, октябре и декабре было выпущено по два номера в месяц). Таким образом, за 2003 год - 17 номеров (всего 100 с начала издания газеты). Формат издания A3, 8 полноцветных страниц. Шрифты удобочитаемые, много фотографий (в среднем 25-30 в каждом номере).

Все выпуски газеты оформлены в едином стиле, с использованием логотипа и фирменных цветов предприятия. Развлекательный контент полностью отсутствует. Большинство тем посвящены производственным достижениям, планам технического перевооружения, развитию информационных технологий и сотрудничеству многочисленных бизнесединиц корпорации как единой структуры. 
Контент насыщен информационными жанрами: в основном это производственные заметки, статистические отчеты, информационные интервью и информационные корреспонденции. Репортажи присутствуют в меньшей степени. Материалов о передовиках производства немного, на первой полосе издания их нет совсем; художественные жанры также практически отсутствуют. Их отсутствие, по нашему мнению, косвенно свидетельствует о тенденциях дегуманизации медиаконтента корпоративной газеты.

Для печатного издания характерно наличие суперрубрик. Всего их 35, в числе традиционных: «Стратегия», «Производство», «Финансы», «Контракты», «Техническое перевооружение», «Наука - производству» и др. В основном на 1-6 полосах представлены тексты о производственных достижениях и перспективах развития корпорации. О людях труда регулярно рассказывают материалы всего одной суперрубрики - «В трудовых коллективах», которая традиционно размещается на 7-й или даже на последней, 8-й странице. Примечательно, что в 2003 году отмечалось 30-летие производственного комплекса - Завода металлоконструкций ОАО «Энергомашкорпорация», но этому событию и материалам о ветеранах производства нашлось место лишь в № 16 (стандартные 8 полос) и № 17 (вышел на 16 полосах) декабрьских выпусков газеты. При этом в каждом номере на первой полосе присутствует анонс на английском языке: небольшая цветная плашка под рубрикой Summary тремя-пятью предложениями передает краткое содержание трех разных газетных материалов производственной тематики.

Необходимо отметить и визуальную перегруженность газетных полос: тяжеловесные заголовочные комплексы с разноцветными плашками и шрифтами, избыточное количество рубрик, множество мелких фотографий (в среднем 5-8 на каждой полосе). Фотографии преимущественно групповые - при этом в фокусе производственное оборудование, а не сотрудники завода, их лица иногда даже плохо различимы. Из 474 фотографий, опубликованных в корпоративной газете «Энергомаш» за 2003 год, человек в центре внимания (портретное фото или достаточно крупный план) находится в 197 случаях (41,6 \%). Уточним, что портретные фотографии обычно маленького размера, не жанровые.

Корпоративную газету можно охарактеризовать как традиционное печатное издание, осуществляющее коммуникацию как с внутренними, так и с внешними целевыми аудиториями, нацеленное на поддержание имиджа «Энергомашкорпорации» как успешного промышленного предприятия.

«Энергомаш» - корпоративное издание ООО «Белэнергомаш - БЗЭМ». В обновленном виде издается с октября 2013 года. Выходит ежемесячно, печатается в Белгороде. В 2018 году издано 12 номеров формата А3, 4 полноцветные страницы, тираж 999 экземпляров. Шрифты удобочитаемые, фотографии преимущественного среднего и крупного размеров (в среднем 2-3 на полосе), текстовый контент преобладает над визуальным. В газете широкие колонки, простая прямая верстка, ограниченное количество шрифтов. В каждом номере присутствует тематическая полоса о производственной деятельности предприятия, важнейших заказах и проектах.

В газете преобладают информационные жанры (заметки, производственные репортажи, информационная корреспонденция, интервью), но частично представлены и художественные жанры (портретные зарисовки, интервью). Контент разделен на тематические рубрики, традиционными из них являются: «Есть такая служба», «Визиты», «Производство: день за днем», «Рационализация», «Новые проекты», «Спорт» и другие. Всего 25 рубрик, из которых можно выделить следующие, относящиеся к материалам о людях труда: «Наши передовики», «Передовики производства», «Знай наших!», «Мир увлечений», «Лучшие из лучших», «С юбилеем!», «Поздравляем с наградой!». Обязательным элементом первой полосы является материал о человеке труда с качественной портретной 
фотографией. Для издания характерны фотографии, на которых в фокусе внимания находятся люди - сотрудники предприятия. Из 115 фотографий, опубликованных в корпоративной газете «Энергомаш» за 2018 год, таких фотографий насчитывается 77 (67 \%).

Однако для современной корпоративной газеты «Энергомаш» такое соотношение уже не свойственно. После вхождения завода в структуру «Объединенной металлургической компании» главным вектором дальнейшего корпоративного развития стала «клиентоориентированность». Этот вектор в настоящее время прослеживается в информационной политике предприятия, корпоративных медиа и внешних коммуникациях.

Особо отметим и усиливающийся интерес к теме роботизации предприятия, в частности, на страницах корпоративной газеты «Территория ОМК» (выходит два раза в месяц) и периодического электронного журнала «ОМК Команда» (выходит ежемесячно или раз в два месяца).

Пример 1. Рубрика «Безопасность». Заголовок «Робот Альберт носит каску».

Лид. Искусственный интеллект поможет сделать производство ВМЗ более безопасным» («Территория ОМК», № 21 (229) от 23 октября 2020 года).

Пример 2. Рубрика «Безопасность». Заголовок «Нажми на кнопку - получишь».

Лид. Робот будет выдавать СИЗ сотрудникам чусовского завода ОМК («Территория ОМК», № 7 (240) от 9 апреля 2021 года).

Пример 3. Рубрика «Перспектива». Заголовок «Не своими руками».

Лид. Руководители чусовского завода анонсировали появление роботов на термическом участке («Территория ОМК», №8 (241) от 23 апреля 2021 года).

Теме роботизации полностью посвящен и выпуск № 3 за июнь 2020 года электронного журнала «ОМК Команда». Характерные заголовки: «Быстрее, меньше, точнее» (Какие рекорды ставят промышленные роботы?), «Нечеловеческий фактор» (Когда «электроники» вытеснят сотрудников ОМК с рабочих мест?), «Вкалывают вместе с человеком» (Заводчане поделились впечатлениями о роботах-коллегах) и другие.

В свете уже перечисленных факторов эта тенденция, однако, не может не настораживать. В корпоративных медиа тема роботизации подается как желание облегчить работу сотрудников предприятия, разгрузить их мозг от рутины однотипных задач, высвободив тем самым время для творчества. Это интересно, ново, за этим будущее... Но почему же тогда на страницах корпоративных СМИ не становится больше этого самого «творчества», материалов о самих людях труда, их человеческих радостях и увлечениях?..

\section{Заключение}

В статье мы обратились к некоторым проявлениям тенденции дегуманизации корпоративного медиаконтента. Можно сделать вывод, что современные цифровые технологии и экономические реалии вносят значительный вклад в процесс трансформации медиасреды и усиление этих тенденций. Это создает необходимость в изучении перспектив минимизации выявленных факторов, негативных эмоций и ассоциаций, вызванных потреблением контента и проецируемых на бренд предприятия и его продукцию. Как отмечает О.А. Важенина, «гуманистические мировоззренческие позиции общества по отношению к личности и своему будущему позволяют осмыслить человека как уникальное явление природы, признать приоритет его субъектности...» [Важенина, 2018, с. 30]. При этом гуманистические ценности остаются едиными для всех сфер общественной жизни и, по нашему мнению, могут быть репрезентированы посредством массмедиа. Корпоративные медиаресурсы способны постепенно встраивать аксиологические модели медиадискурса во все аспекты профессиональной деятельности, описывая позитивные качества, которые являются «человечными» в самом человеке. 


\section{Список литературы}

1. Алексютина О.А. 2018. Понятие и функционально-коммуникативные особенности рекламного контента. Инновации и инвестиции, 4: 198-200.

2. Важенина О.А. 2018. Массмедиа как инструмент гуманистического воспитания общества. Учёные записки ЗабГУ, 13(2): 29-38. DOI: 10.21209/2542-0089-2018-13-2-29-39

3. Выпряжкин Б.С. 2011. Формирование корпоративной культуры предприятий авиационной промышленности в условиях реструктуризации. Автореф. дис. ... канд. эконом. наук. Москва, 24 с.

4. Гусарева Н.Б., Царитова К.Г. 2015. Ценности как атрибут сильной корпоративной культуры. Управление экономическими системами: электронный научный журнал, 5 (77): 28.

5. Кожемякин Е.А. 2013. Массмедиа и обратная связь: точка зрения социального конструкционизма. Научные ведомости Белгородского государственного университета. Серия: Гуманитарные науки, 27 (170): 93-101.

6. Лукина М.М., Вартанова Е. Л., Фольц А.О. и др. 2010. Интернет-СМИ: Теория и практика: Аспект-Пресс. 348 с.

7. Павленко Т.С. 2017. Понятие «контент»: типология, виды и технология получения дидактического контента в образовательном процессе. Известия Волгоградского педагогического университета, 10 (123): 31-35.

8. Полонский А.В. 2018. Медиалект: Язык в формате медиа. Научные ведомости Белгородского государственного университета. Серия: Гуманитарные науки, 37 (2): 230-240. DOI: $10.18413 / 2075-4574-2018-37-2-230-240$

9. Семашкина Н.С. 2020. Ценностные аспекты корпоративного медиадискурса коммерческого предприятия. Вопросы журналистики, педагогики, языкознания, 39(2), 159-168. DOI 10.18413/2712-7451-2020-39-2-159-168

10. Шестеркина Л.П., Лободенко Л.К. 2014. От медиатекста к медиабренду: к вопросу o взаимодействии журналистики, рекламы и PR в конвергентных СМИ. Вестник ЮжноУральского государственного университета. Серия: Лингвистика, 3 (11): 50-55.

\section{References}

1. Aleksyutina O.A. 2018. Ponyatiye I functsionalno-kommunikativniye osobennosti reklamnogo kontentaПонятие и функционально-коммуникативные особенности рекламного контента [Features of advertising content]. Innovation \& Investment, 4: 198-200 (in Russian).

2. Vazhenina O.A. 2018. Massmedia kak instrument gumanisticheskogo obrazovaniya [Mass media as a tool for humanitarian education of society]. Uchyonyie Zapiski ZabGU, 13(2): 29-38 (in Russian). DOI: 10.21209/2542-0089-2018-13-2-29-39

3. Vypryazhkin B.S. 2011. Formirovanie korporativnoy kul'tury predpriyatiy aviatsionnoy promyshlennosti $\mathrm{v}$ usloviyakh restrukturizatsii [Formation of the corporate culture of the aviation industry enterprises in the context of restructuring]. Abstract dis. ... Cand. economy sciences. Moscow, 24 p. (in Russian).

4. Gusareva N.B., Tsaritova K.G. 2015. Tsennosti kak atribut sil'noy korporativnoy kul'tury [Values as an Attribute of a Strong Corporate Culture]. Upravlenie ekonomicheskimi sistemami: elektronnyy nauchnyy zhurnal, 5 (77): 28 (in Russian).

5. Kozhemyakin E.A. 2013. Massmedia I obratnaya svyaz: tochka zreniya sotsialnogo konstruktsionizma [Mass media and feedback: the claims of social constructionism]. Belgorod State University Scientific bulletin. Humanities, 27 (170): 93-101 (in Russian).

6. Luukina M. M., Vartanova E.L., Foltz A.O. et al. Internet media: teoriya i praktika [Internet media: theory and practice]. Moscow: Aspekt-Press, 348 p. (in Russian).

7. Pavlenko T.S. 2017. Ponyatiye kontenta: tipologiya, tipy, I tekhnologiya poluchenia didakticheskogo kontenta $\mathrm{v}$ obrazovatel'nom processe [The notion of content: typology, types and technology to receive the didactic content in the educational process]. Izvestiya Volgogradskogo pedagogicheskogo universiteta, 10 (123): 31-35 (in Russian).

8. Polonskiy A.V. 2018. Medialekt: jazyk v mediaformate [Medialect: language at the media format]. Belgorod State University Scientific bulletin. Humanities, 37 (2): 230-240 (in Russian). DOI: 10.18413/2075-4574-2018-37-2-230-240. 
9. Semashkina N.S. 2020. Tsennostniye aspekty korporativnogo media diskursa kommercheskikh kompaniy [Value aspects of corporative media discourse of commercial companies]. Issues in Journalism, Education, Linguistics, 39 (2): 159-168 (in Russian). DOI 10.18413/2712-74512020-39-2-159-168 (in Russian).

10.Shesterkina L.P., Lobodenko L.K. 2014. Ot mediateksta $\mathrm{k}$ mediabrendu: $\mathrm{k}$ problem zhurnalistiki, reklamy I PR [From Mediatext to Mediabrand: On the Problem of Journalism, Advertising and PR Interaction in Media Convergence]. Bulletin of the South Ural State University, Series "Linguistics", 1 (3): 50-55 (in Russian).

Конфликт интересов: о потенциальном конфликте интересов не сообщалось.

Conflict of interest: no potential conflict of interest related to this article was reported.

\section{ИНФОРМАЦИЯ ОБ АВТОРЕ}

Семашкина Надежда Сергеевна, старший преподаватель кафедры коммуникативистики, рекламы и связей с общественностью института общественных наук и массовых коммуникаций Белгородского государственного национального исследовательского университета, г. Белгород, Россия

\section{INFORMATION ABOUT THE AUTHOR}

Nadezhda S. Semashkina, senior lecturer, department of communication studies, advertising and public relations, Institute of social sciences and mass communications, Belgorod National Research University, Belgorod, Russia. 